\title{
Assessment of the impacts and transmission of coronavirus observed in the Republic of Korea in 2020-2021
}

\author{
Y. S. Chung ${ }^{1} \cdot$ H. S. Kim ${ }^{2}$ \\ Received: 18 February 2021 / Accepted: 30 March 2021 / Published online: 16 April 2021 \\ (C) The Author(s), under exclusive licence to Springer Nature B.V. 2021
}

\begin{abstract}
The pandemic of Coronavirus diseases occurred in the Republic of Korea from 19 January 2020. By March 2020, Korea had reported the second largest number of Coronavirus patients in the world. On the anniversary date (2021), however, with a 51.3 M population, Korea has had $73.115 \mathrm{~K}$ patients with $1.283 \mathrm{~K}$ deaths, and this stands at 86 th in the world. On average, Korea has 14.3 patients per 10,000 people. Air-parcel trajectory analysis and airflows show that in the general westerly region, air parcels and pollutants could flow out and in all directions. This suggests initially that Coronaviruses from source areas in China could transmit to many sink regions and sectors including 228 subdivided counties in Korea. However, there were only relatively small numbers of Coronavirus patients in western sea sides of the Korean Peninsula in comparison with large numbers of Coronavirus disease patients in cities and in eastern sides. In particular, three counties in Korea, including Ong-jin, Mooju and Chang-heung, have zero patients of Coronavirus diseases. This suggests that a long-distance transmission of Coronavirus from Wuhan and other infected cities in China to western Korea likely did not occur. Moreover, there was no evidence on the potential transmission of Coronavirus from neighboring large cities to the above-mentioned isolated counties in Korea which are only $10 \sim 50 \mathrm{~km}$ away. In the biosphere, during the transmission stage, the inactivation of Coronavirus by UV rays appeared to occur effectively in $30 \sim$ $120 \mathrm{~min}$, in agreement with the result of satellite and modeling studies. In turn, the air transmission of Coronaviruses and pollution from China and neighboring cities in Korea apparently had no impact to cause Coronavirus diseases at the 228 counties in Korea. The infection and spreading of Coronavirus diseases to other people in Korea mainly appeared to occur in confined indoor air environments. With the absence and lack of UV rays in indoor environments, Coronaviruses would be active there for hours or days longer than in the outdoor environments.
\end{abstract}

Keywords Coronavirus disease Covid-19 - Transmission of coronaviruses · Impact assessment of pandemic $\cdot$ UV rays and destruction of coronavirus $\cdot$ Statistics of coronavirus diseases $\cdot$ Indoor air quality

\section{Introduction}

In December 2019 a novel Coronavirus disease (Covid-19) began in Wuhan, China. Since 19 January 2020, the Wuhan Coronavirus has had a significant impact on people in the Republic of Korea. After three days, Toronto, Canada also reported patients of Coronavirus disease from China (Schwartz et al. 2020). In February and March 2020, Korea maintained the

Y. S. Chung

kccar1@naver.com

1 Korea Centre for Atmospheric Environment Research, Cheongju 28177, South Korea

2 Korea National University of Education, Cheongju 28173, South Korea second largest number of confirmed patients in the world, as she is a neighboring country downstream east side of China. Presently, world statistics (WorldOMeters 2021) show that Korea has recorded $73.115 \mathrm{~K}$ confirmed cases.

Studies on the long-range transport of Coronavirus from Wuhan and other places in China to the Korean Peninsula are needed to examine the possibility of direct air contamination from the source region. The short-distance transmission of novel Covid-19 in Korea is also studied for a potential cause of the rapid increase in patients in comparison with direct infection within indoor environments. On 20 October 2020, the WHO updated that "more studies are underway to better understand the conditions in which aerosol transmission is occurring outside of medical facilities where specific medical procedures, called aerosol generating procedures are conducted". 
Clearly, there is a need for many studies on the potential cause and transmission of highly contagious Coronavirus diseases in small- and large-scale atmospheric influences. We suggest and conclude that a change in better management is needed on the Coronavirus pandemic in the monitoring of the present world-wide situation. The impact of the Coronavirus pandemic has brought unexpected and abrupt changes to many aspects of our lives.

\section{Statistics of coronavirus diseases}

The first case of a Coronavirus disease was reported on 19 January 2020 in Korea, and the patient arrived directly by air from Wuhan, China. Many Korean people from church activities in Wuhan, China were sick already, and the highly contagious disease was spreading widely and rapidly, especially in the southeastern large inland city, Daegu, Korea. Korea is located just in the leeward side of China where general westerly winds and airflows prevail. When in February and March 2010 Korea reached the second-largest number country in Coronavirus patients, long-range of the Coronavirus became a suspect. On 31 March 2020, Korea had 9786 Coronavirus patients with 163 deaths, and on 1 April there were 9887 cases (Fig. 1a). By 17 May 2020, Korea recorded a sharp increase in Coronavirus disease cases to 11,050 and 262 deaths (WorldOMeters 2021).

On 19 January 2021, on its anniversary of Covid-19, Korea recorded $73.115 \mathrm{~K}$ Coronavirus patients with $1.283 \mathrm{~K}$ deaths out of 51.3 M people (WorldOmeters 2021). According to the statistics, Korea was ranked 86 out of 221 countries in the world by the number of cases.

Figure $1 b$ and $c$ show the number of daily Covid-19 cases and the corresponding trend occurring in Korea from January 2020 to January 2021 given in the world statistics. From February to March, confirmed patients increased rapidly, primarily among church people coming back from China to Daegu city, Korea. Sadly, from due to mismanagement in large group meetings and long weekends, Coronavirus spread in Korea resurged significantly from late November 2020 to the end of January 2021 (Fig. 1b and c).

Table 1 shows Coronavirus disease statistics for 18 countries, providing valuable data to discuss in relation to transmission of Coronavirus diseases. In the world population of 7.836 B people, there were $96.119 \mathrm{M}$ Coronavirus patients and $2.052 \mathrm{M}$ deaths in 221 countries by 19 January 2021 . The USA has the largest number of Coronavirus patients of 24.629 M with $408.6 \mathrm{~K}$ deaths. With $1.439 \mathrm{~B}$ people, China had $88.454 \mathrm{~K}$ patients and 4.635 deaths, and China had the greatest number of cases until the summer of 2020.

On the Coronavirus anniversary date, Korea had 14.3 Coronavirus patients per each 10,000 people (cf: 741.7 in the U.S.A.). In cities, the number of Coronavirus patients were
$2 \sim 3$ times higher. Korean local governments are divided into 228 with the name of small city, Ku and Koon, as small county. Each local government has about 20,000 300,000 people in the rural and urban areas, and it manages the monitoring of Coronavirus patients and then reports the result to provincial and central governments for making the final decision on the pandemic crisis.

From the examination of statistics on Coronavirus disease outbreaks, we found three particular local counties, Koon. They are Ong-jin Koon, Mooju Koon and Chang-heung Koon which are located in the sea and a mountainous remote area separated from large urban centres. During the last one-year of the Coronavirus disease period, strikingly, Ong-jin has recorded zero confirmed patients. In addition, Mooju and Chang-heung had each only one patient of Covid-19. However, one confirmed patient in Mooju moved from another place and the patient in Chang-heung also came from Russia by air.

Furthermore, Ong-jin has a population of 21,227, Mooju has 24,036, and Chang-heung has 36,020 inhabitants. According to former statistics, on average Ong-jin should have at least 30 Covid-19 patients, Mooju 34, and Changheung should have at least 51 patients. This suggests that there were large differences in numbers of Covid-19 patients between rural and urban areas. According to the national analysis, in the west coast provinces and cities, it was recorded on 8 May 2020 that the number of Coronavirus patients was a mere 28 in Incheon city, Choongnam Province was 10, and Cheonnam Province was only 9. These are relatively low values in comparison with high numbers of patients in eastern side provinces and cities. Another study on the assessment and impact of Covid-19 with small-scale transport and indoor environments is discussed elsewhere (Chung 2021). Yet, further studies are needed in atmospheric analysis on the transmission of novel Coronavirus in the west and east environments.

\section{Atmospheric analysis and transmission of coronaviruses}

\section{Air trajectory analysis}

Coronavirus was studied in relation with transport of particulate matter (PM10) in Italy (Martelletti and Martelletti 2020). However, no evidence indicated large-scale transport of air pollutants and virus there. Many studies on the transport of air pollutants in all scales have been done. Transport of air pollutants from a few hundred to over several thousand kilometers occurs in many lands and over the oceans. Evidence on the transport of air pollutants including dust and toxic gases in East Asia is well documented (e.g., Chung and Kim 2008). The variety of viruses, bacteria and insects can be included and contained in the mass of air pollutants (Maki et al. 2008; 
Fig. 1 a. A profile showing Korean Coronavirus cases on 17 May 2020 (WorldOmeter's COVID-19 data). b. Daily new confirmed patients observed In Korea from January 2020 to January 2021 (WorldOmeter's COVID-19 data). c. The trend of Coronavirus diseases reported in Korea from January 2020 to January 2021 (WorldOmeter's COVID-19 data) a

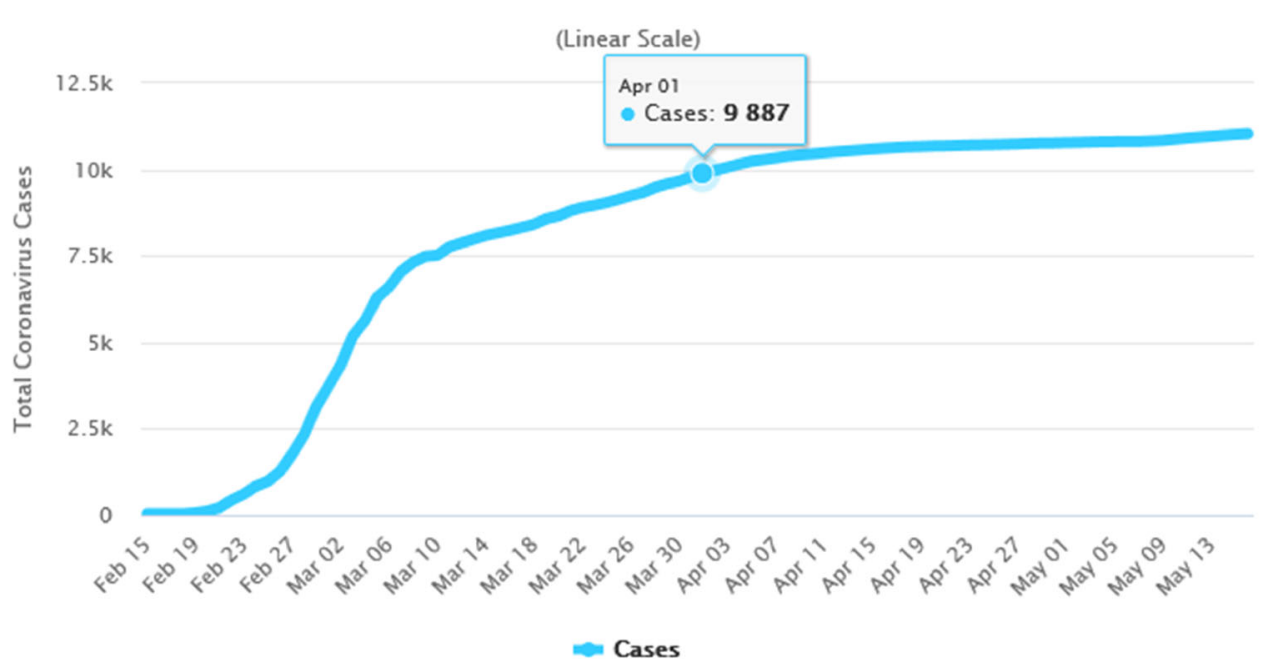

Daily New Cases

b

Cases per Day

Data as of 0:00 GMT +0

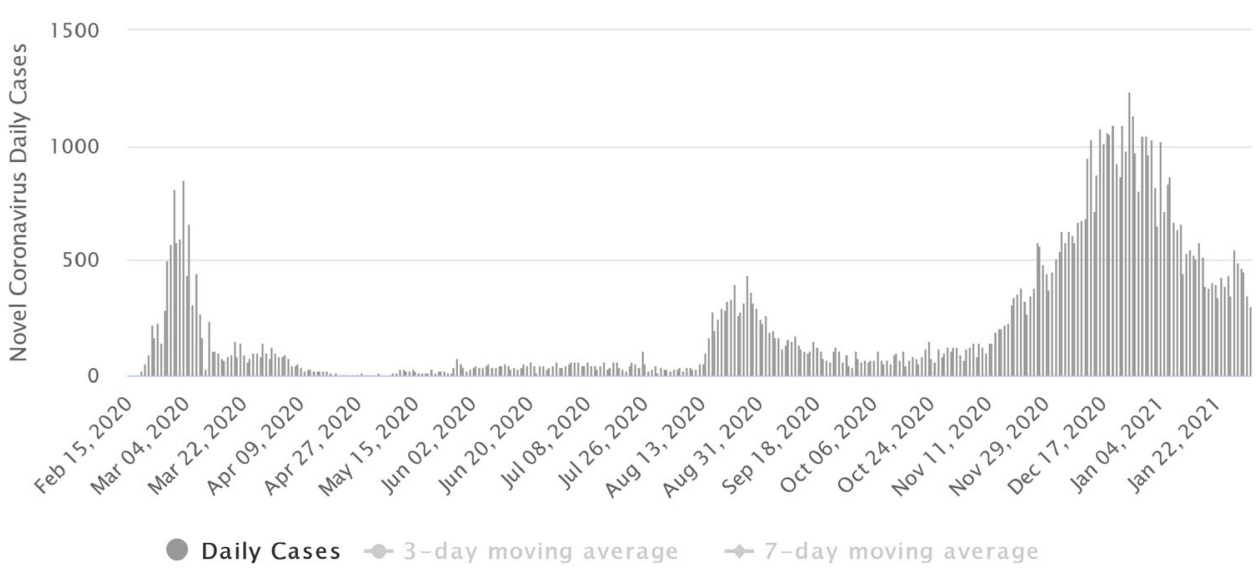

C

Total Cases

(Linear Scale)

$100 k$

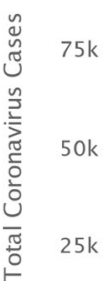

$a^{2} a^{2} a^{2} a^{2} a^{2} a^{2} a^{2} a^{2} a^{2} a^{2} a^{2} a^{2} a^{2} a^{2} a^{2} a^{2} a^{2} a^{2} a^{2} a^{2} a^{2} a^{2} a^{2} a^{2} a^{2} a^{2}$

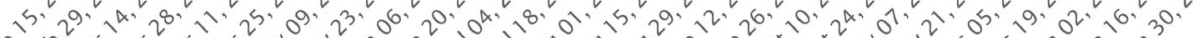

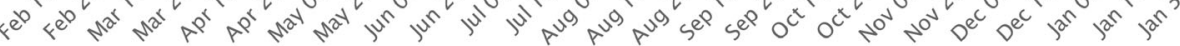

Cases 
I

$\stackrel{2}{2}$

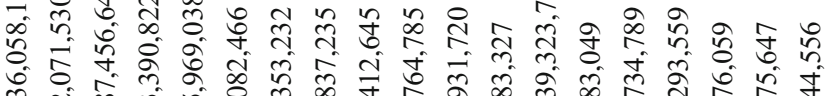

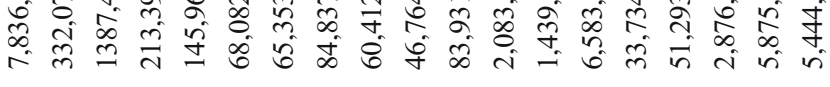

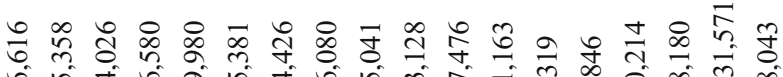

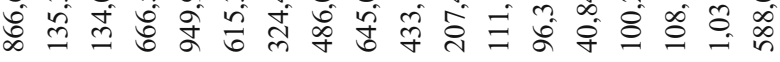

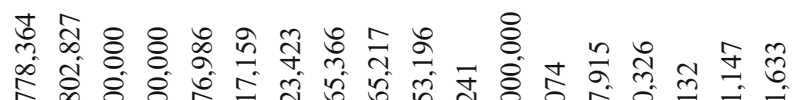

क्ते

ฉั

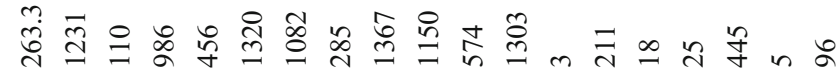

оे

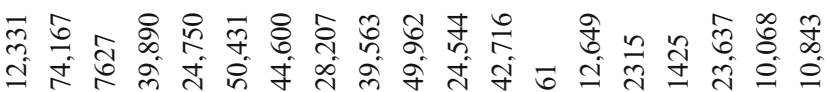

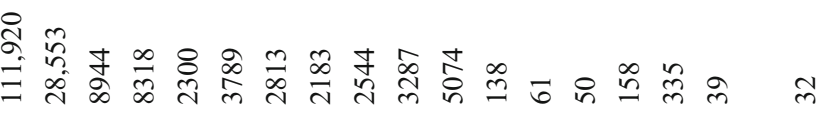

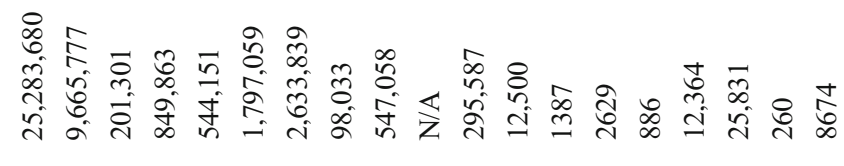

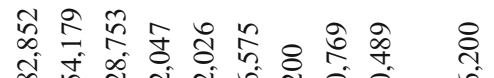

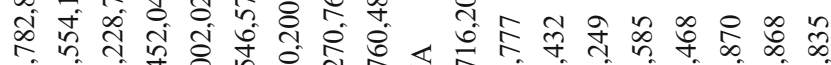

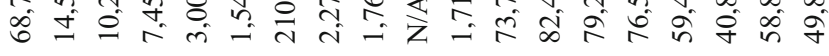

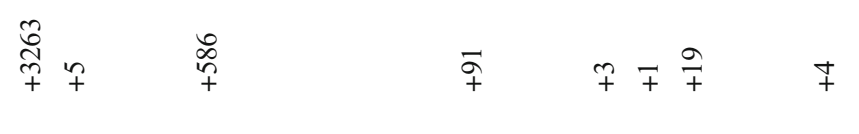

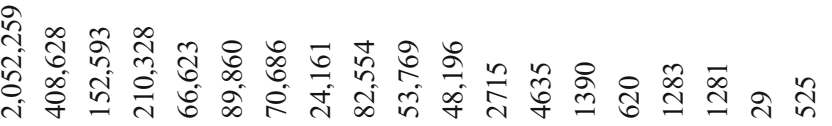

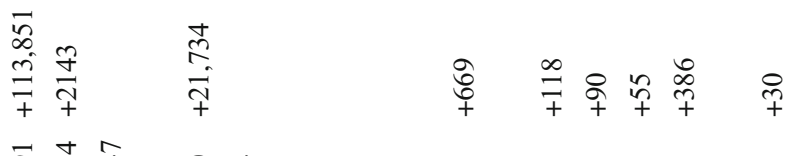

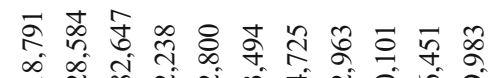

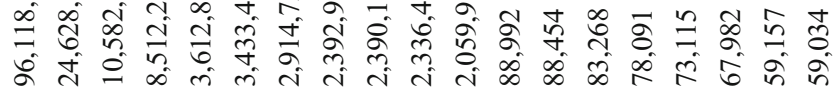

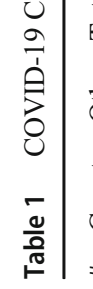

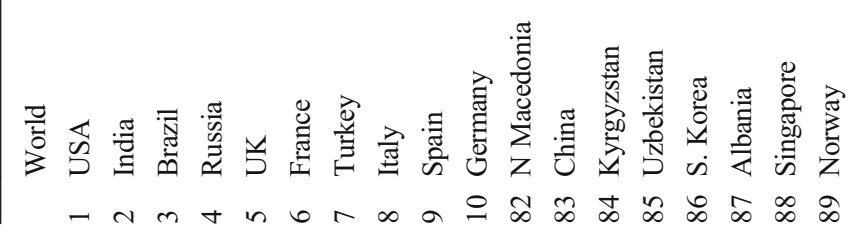


Fig. 2 Low clouds and masses of air pollutants formed in eastern China crossing the Yellow Sea and approaching the Korean Peninsula, observed in a satellite image (16 November 2020)

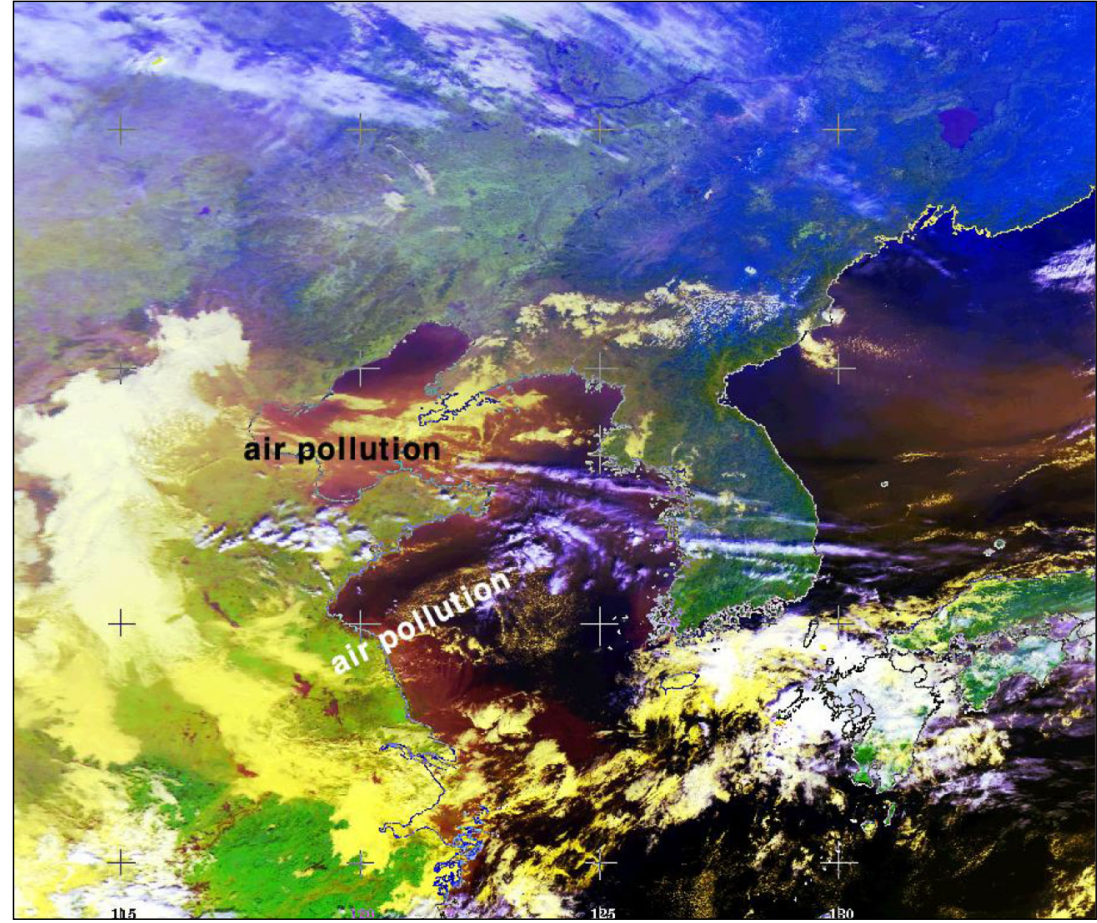

Domingo et al. 2020) from China to the Korean Peninsula, particularly with westerlies.

Figure 2 includes a satellite image showing low level clouds and masses of air pollutants formed in east China. With moderate winds and airflow of $5 \mathrm{~m} / \mathrm{s}$, air pollutants and viruses formed there could cross the Yellow Sea to reach the Korean Peninsula in about 1 day. Figure 3 also shows that a giant mass of $\mathrm{NO}_{2}$ cloud is formed over China (Martelletti and Martelletti 2020) and is approaching the Korean Peninsula. With smoke and air pollution plumes coming out in East China and with moderate airflow situations, monitoring stations in Korea do often record high values of air pollutants. Undoubtedly, numerous species of bacteria and viruses are also contained in those kinds of air pollution masses.
Virus has been detected on particles of air pollution by scientists (Domingo et al. 2020). However, it is not yet known if the novel Coronavirus remains viable on pollution particles and in sufficient quantity to cause disease. The possibility to be carried over longer distances and increase the number of people infected with Coronaviruses are also not known and yet to be studied.

In the westerly atmospheric regime, air parcel and air pollutants from east China to the west coast of Korea via the Yellow Sea arrive in about $12 \sim 48 \mathrm{~h}$ with the airflow of $2 \sim$ $5 \mathrm{~m} / \mathrm{s}$ strength. The width and distances of the Yellow Sea between China and Korea are from about 350 to $800 \mathrm{~km}$. Figure 4 plots the forward and backward trajectories of one month in 2020 (NOAA 2020). In Fig. 4a and b, forward
Fig. 3 Eastward transport of $\mathrm{NO}_{2}$ mass and plumes from China to the Korean Peninsula (Martelletti and Martelletti 2020)

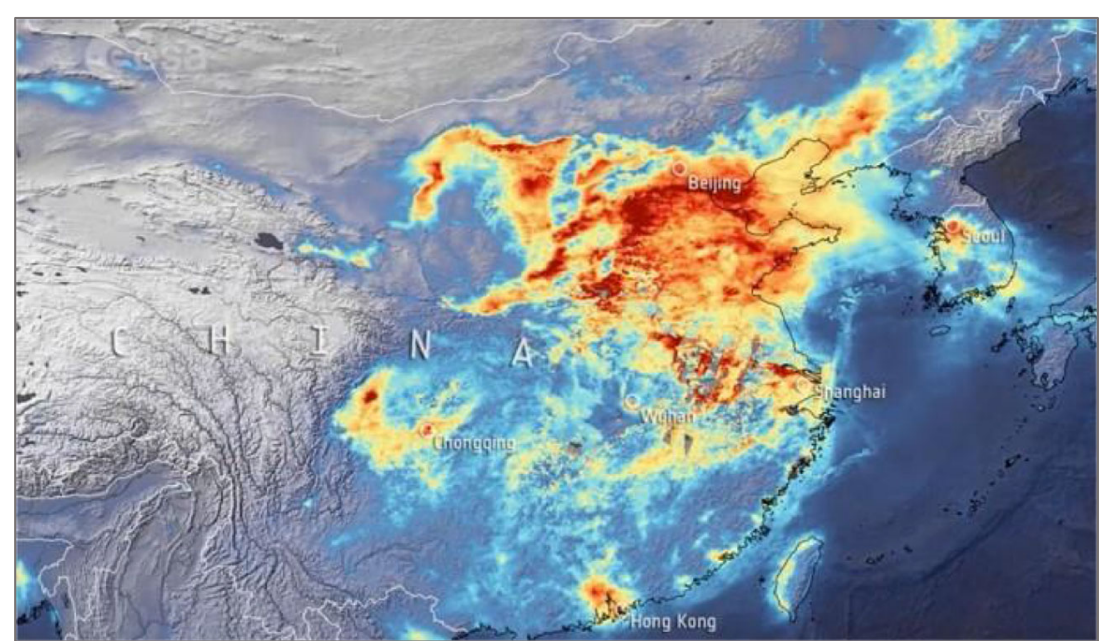




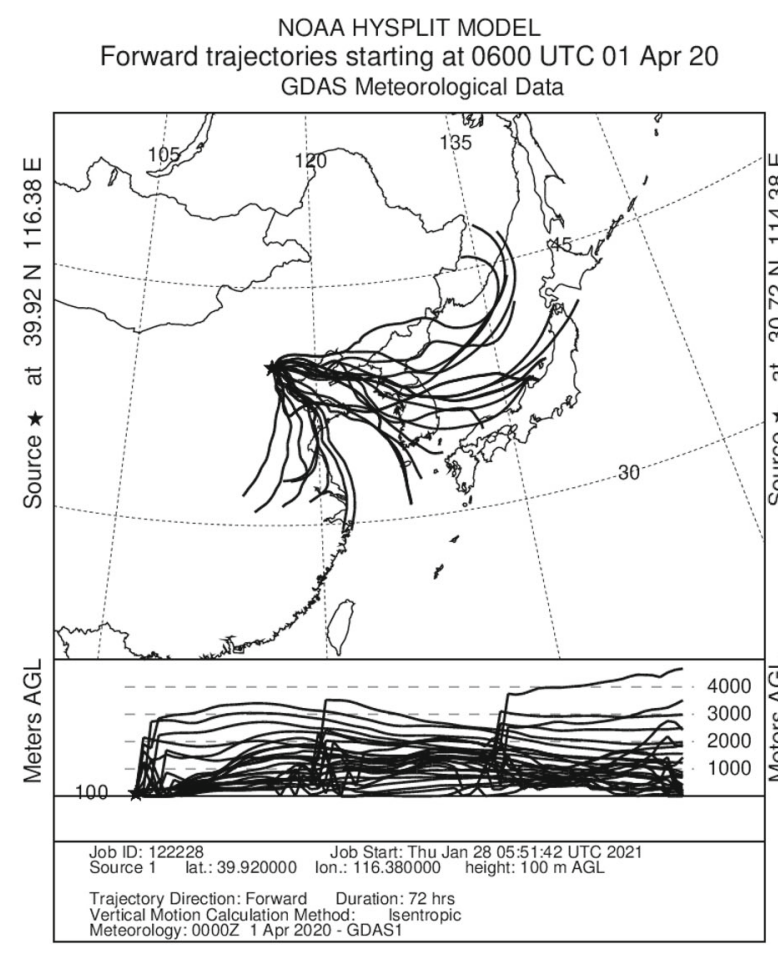

a

NOAA HYSPLIT MODEL

Backward trajectories ending at 0600 UTC 30 Apr 20

GDAS Meteorological Data

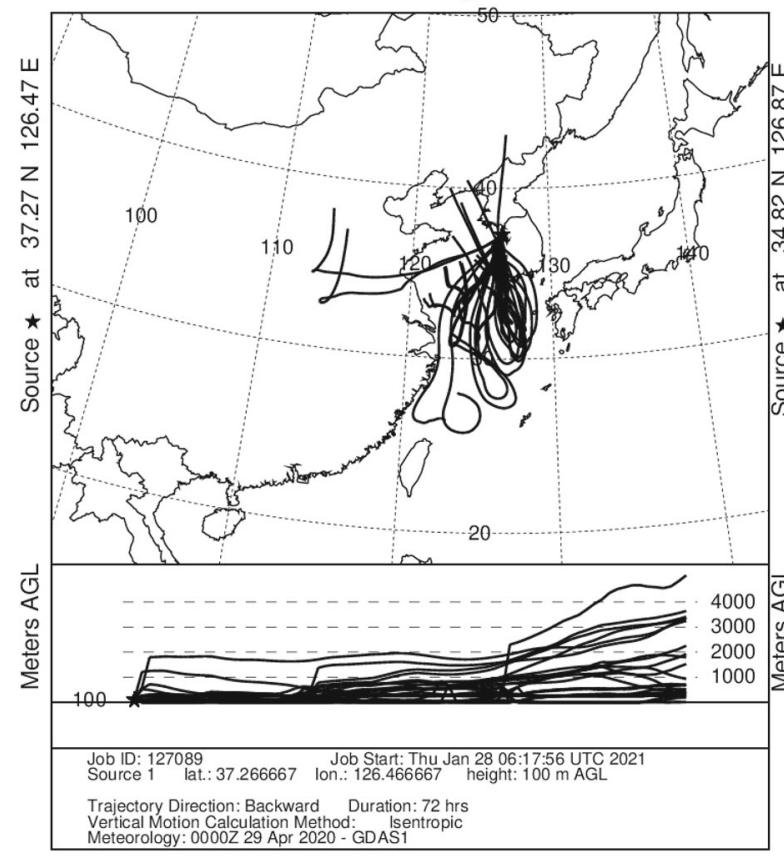

C
NOAA HYSPLIT MODEL

Forward trajectories starting at 0600 UTC 10 Feb 20 GDAS Meteorological Data

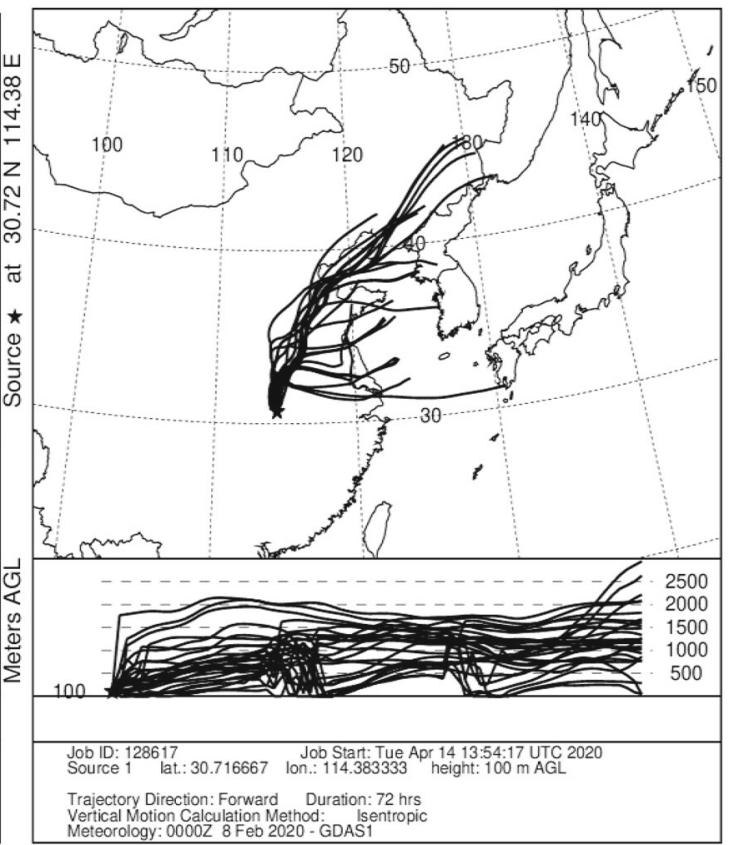

b

NOAA HYSPLIT MODEL

Backward trajectories ending at 0600 UTC 10 Feb 20 GDAS Meteorological Data

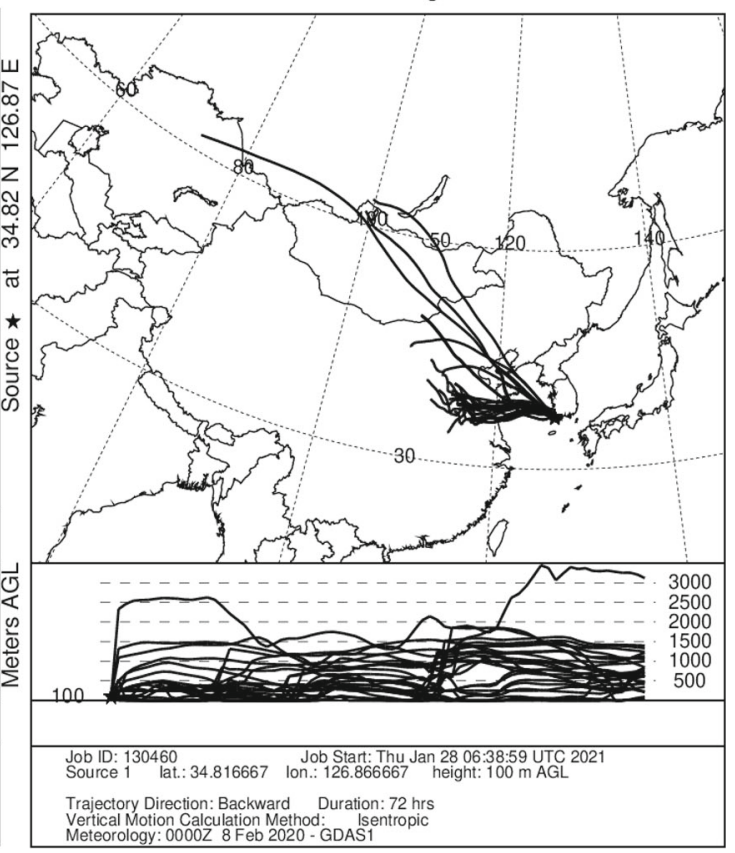

d

Fig. 4 Forward and backward trajectories of one month at a) Beijing and b) Wuhan, China; c) Ong-jin and d) Chang-heung, Korea, starting and ending at $100 \mathrm{~m}$ above the ground

trajectories starting at Beijing and Wuhan, China are shown, while backward trajectories at Ongjin and Chang-heung,
Korea for a month are plotted in Fig. 4c and d. It will be seen that air parcels and air pollutants from a source area would be 


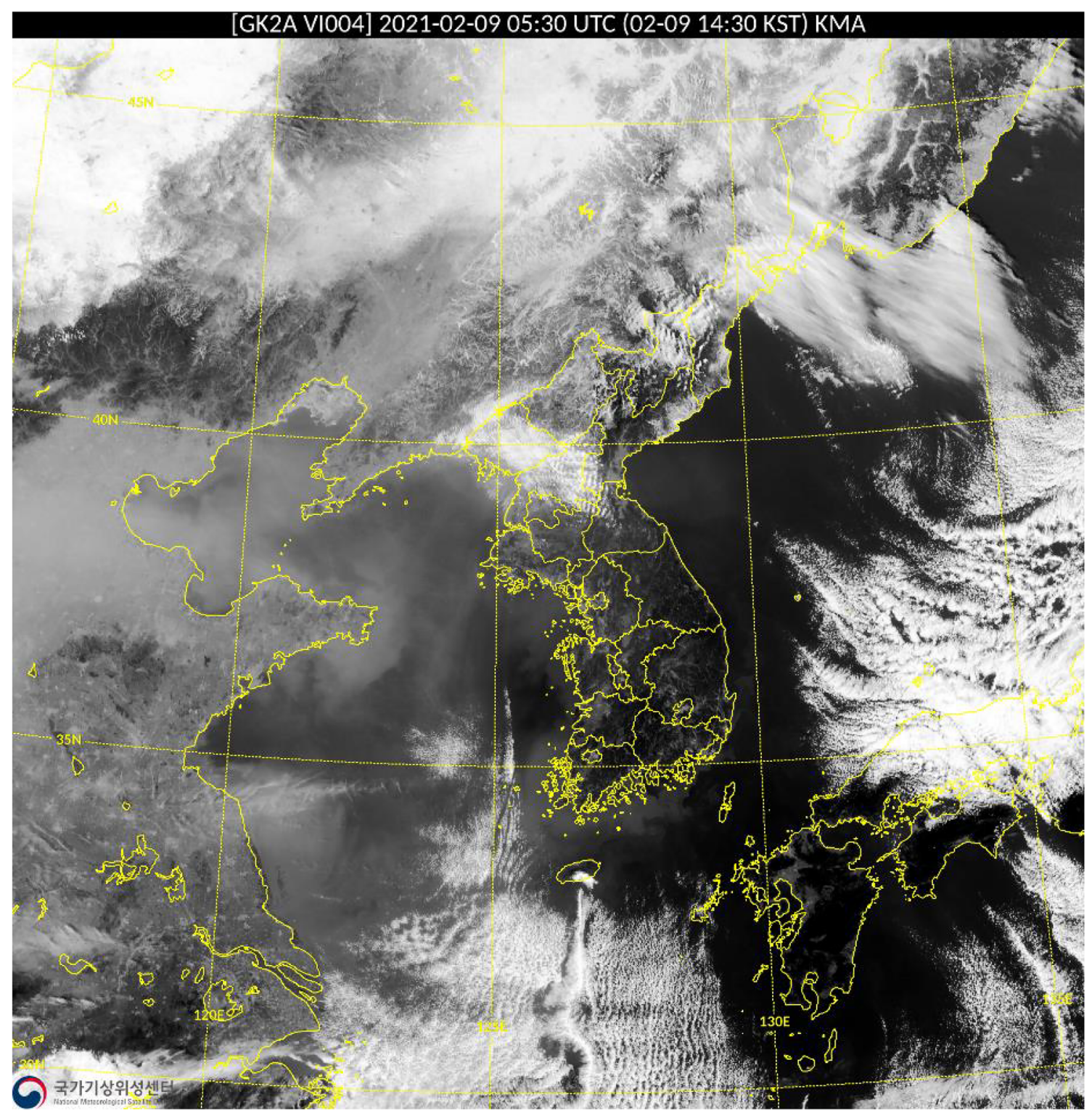

Fig. 5 A satellite image detected the solar ray of $470 \mathrm{~nm}$ showing the cloudy and near UVA atmosphere in East Asia. (Korea Meteorological Administration)

flowing to many directions to sink areas. During the past oneyear period, Coronavirus from source areas would have reached to potential sink areas in Korea to cause sickness. This possibility is to be confirmed. In order to find the possibility of said Coronavirus activities in the pollutants, air samples from the west coast of Korea should be studied further by microscopic analysis in the future.

Nevertheless, from the statistical analysis of Coronavirus diseases patients, we have found that in the remote islands and mountain areas, Covid-19 patients are much less than those in large cities and inland counties. In addition, in the west coast regions of Korea facing east China, there are fewer Coronavirus patients in comparison with those of eastern sides in Korea.

\section{Air transmission of coronavirus and UV rays}

We have investigated whether Coronavirus could be carried more widely over long distances with air pollution. It is thought that viruses causing bird flu, foot-and mouth and Coronavirus diseases could be carried by air over considerable distances. We should now consider the atmospheric impacts of solar radiation on the (life) span of virus protein.

Solar rays include ultraviolet (UV) spectrum, and these are subdivided to UVA $315 \sim 400 \mathrm{~nm}$, UVB $280 \sim 315$, and UVC in $100 \sim 280 \mathrm{~nm}$. Scientists have shown that these UVA and UVB rays penetrate deep to the biosphere of the lower atmosphere. It is known that in the stratosphere UVC light on any particle and object which contain the virus protein breaks down 
in short time, $\sim 10 \mathrm{~s}$. Importantly, according to many studies in laboratory and atmospheric modeling (Hessling et al. 2020; Ratnesar-Shumate et al. 2020; Herman et al. 2021), the UVA and UVB rays "rapidly inactivate" the Coronavirus effectively in the lower atmosphere in $30 \sim 120 \mathrm{~min}$.

Figure 5 shows solar ray detection in $470 \mathrm{~nm}$ spectrum, near UVA ray. A good portion of UVA can be absorbed in the clouds but some penetrates the moist atmospheric layer to reach ground level. There are considerable amounts of UVA and UVB rays in the biosphere where we conduct outdoor living activities.

From the former analysis of air parcel and air pollution trajectories, in the westerly wind regime air pollution and Coronavirus are thought to harbor from source regions to sink areas. However, we have observed zero Covid-19 patients in the remote islands and mountain sectors. In addition, in the west coastal areas of the Korean Peninsula, Coronavirus disease occurred in relatively small numbers in comparison with the eastern region and large cities. This contrast indicates that long-distance transmission of Coronaviruses is apparently not possible over the Yellow Sea, because those viruses were destroyed over the Yellow Sea effectively by UV rays at least in $1 \sim 2 \mathrm{~h}$, as laboratory and modeling studies suggested.

\section{Discussion}

The monitoring of air pollution has been done both in the indoor and outdoor environments. It is clear that Coronaviruses in the biosphere are very sensitive to UV rays, according to our large-scale analysis of air parcels and Coronavirus statistics. Repeatedly, in the outdoor environment of the planetary boundary atmosphere, Coronavirus is destroyed effectively with UV rays in a relatively short time, $30 \sim 120 \mathrm{~min}$, as was found in many studies.

According to our analysis on the possibility of the largescale transport of air pollutants and viruses from Wuhan and neighboring areas of having many Coronavirus patients, Coronavirus was not transmitted to residents in other counties in Korea; islands, Ong-jin Koon, etc. In fact, Coronaviruses would take at least $12 \mathrm{~h}$ to cross the Yellow Sea to Korea, and during the airborne transport all of them would likely be destroyed completely on the Yellow Sea air by the UV rays. Coronaviruses are known to be highly UV sensitive in the biosphere, and simulated sunlight rapidly inactivates Coronaviruses (Hessling et al. 2020).

In Ong-jin there are 21,227 residents in 23 islands, and so far, they have "zero" Coronavirus patients. Those residents in islands travel to the inland only by ferries, and incoming tourists were strictly monitored for Coronavirus. Three small islands of Ong-jin are located at about $5 \mathrm{~km}$ near the large Incheon International Airport. Also, the nearby large city, Incheon has recorded 3777 Coronavirus patients, while the
Kyounggi Province has maintained 19,544 patients by 29 January 2021. This clearly indicates the negative air transmission impact of Coronaviruses to residents living in 23 islands of Ong-jin county.

In addition, if atmospheric transmission of active Coronaviruses, from nearby cities of Cheonju and Kwangju, was possible for more than one hour to Mooju and Changheung Koon, there would have been at least $34 \sim 51$ patients according to the mean values of Covid-19 statistics of Korea. Instead those counties have "zero" patients. These confirm that the UV ray destruction of Coronaviruses in the lower biosphere was actively occurring in short distances in one hour. Ratnesar-Shumate et al. (2020) have carried out laboratory experiments and discussed that $90 \%$ of infectious virus is inactivated every $6.8 \mathrm{~min}$ in the simulated air. With natural sunlight, the infectious virus would be inactivated faster. The atmospheric transmission of the active Coronavirus over the Yellow Sea to over $1 \mathrm{~km}$ and over $1 \mathrm{~h}$ appears unlikely in nature, except during night time when the intensity of UVA and UVB is known to be at its minimum. However, an airmass containing Coronavirus would take at least $12 \mathrm{~h}$, or more to cross the Yellow Sea. These suggest that the wide spreading of the Coronavirus occurred mainly in indoor environments from people to people directly. Assessment on the possibility of short distance transport of Coronaviruses is further studied and presented elsewhere (Chung 2021).

Furthermore, it should be noted that the aerospace and sea ports of Korea are opened and travelers are still moving in and out from various ports. Korea reported about $20 \sim 30$ Coronavirus patients per day among foreign travelers. Even with zero Coronavirus patients reported in China, we still find about 10 or more Coronavirus patients per day coming from there. Both Taiwan and New Zealand reported relatively small numbers of Coronavirus patients. Importantly, Taiwan is situated east-southeast across the Formosa Strait from cities of Xiamen and Fuzhou in China, and the distance is about $\sim 150 \mathrm{~km}$. Albeit, the numbers of confirmed Coronavirus disease in Taiwan are mere 915, and New Zealand are 2307 in comparison with 88,454 in China and 28,842 in Australia, respectively. Their airports are closed to all travelers, and direct contact with patients in other countries are strictly prohibited; thus, they do manage to minimize the number of Coronavirus patients. These also confirm that negative impact of large-distance atmospheric transmission of Coronavirus to the islands of Taiwan and New Zealand, which are away from China and Australia.

It is observed that the Coronaviruses arrived including in Italy, Spain, Germany, the UK and Canada plus the USA were spreading widely and in strength. Even in Korea, as was discussed earlier (Fig. 1b and c), the number of Coronavirus patients were increasing drastically from late November of 2020, and that it was also reported that Covid-19 is speedy and strength in transmission of Coronavirus diseases to other 
people in Korea. In December 2020, the Covid-19 spreading in many countries including the UK, South Africa, the USA, Japan and Korea has gone mutation processes (14 December in the UK; WHO News). This is ended to spread the Variants of Coronavirus over 145 countries out of 221 nations, as of 2 February 2021; and we start to call it in a convenient way, Covid-20 V. Importantly, the plausible cause of the occurrence and rapid spreading of Covid-20 V in Korea from November 2020 to January 2021 (Fig. 1b and c) is not known yet and should be investigated further.

In statistics, the Covid-19 and Covid-20 V were not distinguished and included as the uniform identity in the national numeration of Korea. The mutation of Coronavirus seems to develop further in many lands, and the virus activation and transfer occur from human to domestic animals (August 2020, Denmark). It is also predicted that Covid-20 V will be transmitted to "wild" animals and that a boomerang effect and related impact to humans will occur in the foreseeable future.

\section{Conclusions}

From the anniversary of the first Coronavirus patient in Korea, this study is carried out to learn knowledge associated with the Coronavirus pandemic during the first year. From the examination of statistical data on the number of Coronavirus disease patients in Korea, we find that there are large discrepancies in regions and in counties. Importantly, in a few remote counties, located away both from China and large urban areas of Korea, we have recorded "zero" Coronavirus patients, or only minimum numbers during the last one-year period.

We have observed that large-scale transmission of coronaviruses was apparently not occurring with the effective destruction by atmospheric UV rays. We conclude that a good portion of Coronavirus during the transmission over the Yellow Sea was destroyed and inactivated in $1 \sim 2 \mathrm{~h}$. The UV rays would prevent the virus to be transmitted over longer distances from China, and they played a negative role in the number of people infected in Korea.

Statistical analysis on Coronavirus patients in 228 administrative counties of the present atmospheric impact study has revealed that people's mingling in indoor environments and incoming tourists are main sources of spreading Coronavirus diseases widely in Korea. Office and work-place environments with confined air spaces are believed to be the main sources for the further contamination of the Coronavirus loadings. In turn the indoor air and surfaces contaminated with Covid-19 and Covid-20 V viruses from infected people are main causes for spreading viruses to others.

Air pollution particles carrying the virus further afield is an important and interesting topic. We find that Coronavirus transmission is not likely occurring over large distances in the actual biosphere, and this study should be repeated by more scientists (Chung 2021). Although we have gained some knowledge on the impact of UVC and surfaces in the stratosphere, many laboratory studies including numerical modeling on the impact of UVA and UVB should continue further for the practical application to the biosphere.

Acknowledgements Many useful inputs and thoughts are given kindly by Profs. A Steinemann and P Gowaty. Financial support will be provided by the Korea Met Admin and the National Research Foundation of Korea.

\section{References}

Chung YS (2021) Assessment of coronavirus disease, the nose pollutionfilter, fermented spicy kimchee and peppery hot soup consumed in Korea. Int J Air Qual Atmos Health:14 (under review)

Chung YS, Kim HS (2008) Observations of massive air-pollution transport and associated air quality in the Yellow Sea region. Int J Air Qual Atmos Health 1-2:69-79. https://doi.org/10.1007/s11869-0080014-y

Domingo JL, Marquès M, Rovira J (2020) Effects of air pollutants on the transmission and severity of respiratory viral infections. Environ Res 187. https://doi.org/10.1016/j.envres.2020.109861

Herman J, Biegel B, Huang L (2021) Inactivation times from 290 to $315 \mathrm{~nm}$ UVB in sunlight for SARS coronaviruses CoV and CoV2 using OMI satellite data for the sunlit earth. Int J Air Qual Atmos Health 14-2:217-233. https://avdc.gsfc.nasa.gov/pub/DSCOVR/ JayHerman/COVID-19/

Hessling M, Hönes K, Vatter P, Lingenfelder C (2020) Ultraviolet irradiation doses for coronavirus inactivation - review and analysis of coronavirus photoinactivation studies. GMS Hyg Infect Control. https://doi.org/10.3205/dgkh000343

Maki T, Susuki S, Kobayashi F, Kakikawa M et al (2008) Phylogenetic diversity and vertical distribution of a halobacterial community in the atmosphere of an Asian dust (KOSA) source region, Dunhuang City. Int J Air Qual Atmos Health 1-2:81-89. https://doi.org/10. 1007/s11869-008-0016-9

Martelletti L, Martelletti P (2020) Air pollution and the novel Covid-19 disease: a putative disease risk factor. SN Compr Clin Med 2:383387. https://doi.org/10.1007/s42399-020-00274-4

NOAA (2020) Air resources laboratory: HYSPLIT - hybrid single particle Lagrangian integrated trajectory model (noaa.gov). <https:// www.arl.noaa.gov/HYSPLIT_info.php>

Ratnesar-Shumate S, Williams G, Green B, Krause M, Holland B, Wood S, Bohannon J, Boydston J, Freeburger D, Hooper I, Beck K, Yeager J, Altamura LA, Biryukov J, Yolitz J, Schuit M, Wahl V, Hevey M, Dabisch P (2020) Simulated sunlight rapidly inactivates SARS-CoV-2 on surfaces. J Infect Dis 222-2:214-222. https://doi. org/10.1093/infdis/jiaa274

Schwartz KL et al. (2020) Lack of Covid-19 transmission on an international flight. CMAJ 192-15, April 14, https://oi.org/10.1503/cmaj. 75015 (also, Silverstein WK et al., lancet 2020)

WorldOMeters (2021) Covid-19 Coronavirus pandemic: https://www. worldometers.info/coronavirus/. Accessed 19 Jan 2021

Publisher's note Springer Nature remains neutral with regard to jurisdictional claims in published maps and institutional affiliations. 